\title{
Clinical quality management in telenuclear medicine
}

\author{
Claudine Als • Angelika Bischof Delaloye
}

Received: 3 January 2007 / Accepted: 4 January 2007 / Published online: 19 April 2007

(C) Springer-Verlag 2007

A new subject of huge economic interest is being born: telemedicine. Dedicated journals are emerging, literature is expanding and societies of interest are being created [1]. Web-based e-medicine is increasingly becoming a strategic tool in health care delivery worldwide $[1,2]$. There is a scarcity of specialized medical expertise in distant rural regions of emerging countries as well as among human communities living apart, e.g. in the Navy, or in remote places in harsh physical environments, e.g. the Arctic or Antarctic. In such geographical regions with low population densities, where, for instance, "circuit riders" have been travelling from small town to small town in order to interpret imaging findings among all sorts of other tests, rapidity and competence of expert reading may be increased by distant access to medical data [3].

Practical e-medicine applications include the follow-up of rare clinical conditions (telefollow-up), the seeking of a second opinion by rural (teleconsultation) or navy doctors (navy telemedicine), expert diagnosis of dermatological conditions (teledermatology) [4] and distant reading of radiological (teleradiology) or nuclear medicine images (telenuclear medicine). Moreover, continuous medical

\section{Als}

Department of Nuclear Medicine, Clinique Ste Thérèse,

Grand-Duchy of Luxembourg, Luxembourg

\section{Als $(\square)$}

Institute of Clinical Chemistry, Inselspital, University of Bern, Freiburgstrasse, 3010 Bern, Switzerland

e-mail: claudine.als@insel.ch

e-mail: claudine.als@cst.lu

\section{A. Bischof Delaloye}

Department of Nuclear Medicine,

Centre Hospitalier Universitaire Vaudois,

Lausanne, Switzerland education programmes (tele-education) [5] may be based on evaluation of clinical or dermatological cases (dermanet) [6] or on live surgical procedures (telesurgery) [7]. Clinical applications have been described in the monitoring of cardiac parameters (telemonitoring or telecardiology), in the monitoring of under-served populations (telehomecare), in the surveillance of daily living activities in elderly people in nursing homes using an infrared motion detection system (telesurveillance) [8], in the screening of diabetic retinopathy using digital fundus photography, etc.

Besides the broad concepts of "telemedicine" and "internet medicine", a ready-to-use "tele-terminology" covering diverse aspects of medical expertise is emerging, with original terms such as telespecialist, teledoctor, teleexpert, telepresence, telehealth and evidence-based telemedicine. These terms are partially self-explanatory with regard to technical potential. However, several fundamental questions relating to clinical quality considerations remain without satisfying answers. In telenuclear medicine, the problem lies mainly in the dissociation between the acquisition of clinical and imaging data by a local doctor and their interpretation by a distant expert.

In traditional bedside or ambulatory medicine, the physical proximity and the human relation between doctor and patient are important, resulting in the provision of relevant information via the clinical history and physical examination that may be essential for study interpretation. Functional imaging is sensitive to all sorts of disturbances. FDG scans, which are subject to all manner of possible causes of false positive and false negative results, are but one prominent example. A simple bone scan may raise as many questions as it answers. Such a scan performed in a young patient with resistant pain of the left lower extremity, for instance, may show decreased activity of all bones of the left leg: Is this the expression of a congenital or acquired 
condition leading to hypo-/atrophy? Is it due to reflex sympathetic dystrophy, in which decreased uptake is known to occur especially in young patients? Is it simply due to analgesic sparing of the left lower limb? Was there an error in the description of symptoms and is the pain instead on the right side, where uptake would then be increased? Are the subjective complaints of the patient corroborated by objective clinical signs? Observing the patient's gait while talking with him may clarify the situation and help in weighing the respective relevance of symptoms. What the patient does and does not relate, and the sequence and tone employed, are relevant clues that greatly improve the interpretation of functional imaging studies.

In telemedicine, the crucial problem is the physical distance between expert and patient. This is true for medical specialities in general, and for nuclear medicine in particular. As the internet technically allows interpretation of digital scintigraphic images from outside the department of nuclear medicine, a medical report may theoretically be issued without any personal interaction between the medical doctor and the patient. In such a situation, the objective and intuitive clinical elements, as well as the sociocultural background, are rarely fully communicated to the interpreting physician, who depends on an intermediate professional to provide him with relevant clinical data and to answer additional questions. Without such an intermediary, telenuclear medicine might be reduced to interpretation with only partial or biased knowledge of the clinical condition; under these circumstances it would be the image rather than the clinical condition of the patient that is evaluated, entailing the inherent risk of loss of diagnostic impact and thus credibility.

Integration of patient data with scintigraphic findings is crucial when drawing clinical conclusions. After having been briefly raised at the EANM congress in Istanbul (Members' Assembly, October 18, 2005), the topic was discussed at an intermediate EANM assembly of national delegates in Vienna (March 19, 2006). There was a consensus that failure to consider clinical details, i.e. in the absence of a multidisciplinary approach, might frequently give rise to errors of judgement. It was concluded that the clinical condition of a patient (clinical indication, specific history, findings of a clinical examination where possible, clinical conclusion, comparison with previous examinations) should systematically form a part of the medical report of nuclear medicine procedures. Good clinical practice $[9,10]$ must be the basis for telenuclear medicine as well as for traditional bedside medicine.

It is in the interest of the nuclear medicine speciality that telenuclear medicine conforms to the legal requirements of the practice of medicine in any target country and to the ethical standards in any cultural setting. Great care should also be taken to guarantee the confidentiality of all data transmitted. Sound comprehension of the socio-cultural habits and of the native language of the target country is required. Ethics and credibility in telenuclear medicine depend on the careful and transparent integration of clinical and technical data into the reporting process. Therefore, telenuclear medicine should be practised on a routine basis only when communication with the doctor who saw and examined the patient and who controlled the technical procedures of the examination is excellent. The respective tasks, names, affiliations and qualifications of the reporting doctor and the first-line doctor should be openly declared in the report. Questions of liability, reimbursement etc. have to be clarified as well. These conditions must be met in order for telemedicine to contribute adequately in solving the patient's problem, to achieve optimal transparency and cost-benefit relation, and to comply with the moral and legal rights of patients.

\section{References}

1. Smith AC. Telemedicine: challenges and opportunities. Expert Rev Med Devices 2007;4:5-7.

2. Ferguson EW, Doarn CR, Scott JC. Survey of global telemedicine. J Med Syst 1995;19:35-46.

3. Latifi R, Ong CA, Peck KA, Porter JM, Williams MD. Telepresence and telemedicine in trauma and emergency care management. Eur Sur 2005;37:293-7.

4. Klotz J, Muir L, Cameron C, Delaney L. Monitoring a remote phototherapy unit via telemedicine. J Cutan Med Surg 2005;9: $47-53$.

5. Lee BR, Bishoff JT, Janetschek G, Bunyaratevej P, Kamolpronwijit W, Cadeddu JA, et al. A novel method of surgical instruction: international telemonitoring. World J Urol 1998;16:367-70.

6. Herrmann FE, Sönnichsen K, Blum A. Teledermatologie versus Konsildiagnosen-eine vergleichende Untersuchung von 120 Konsilien. Der Hautarzt 2005;56:942-8.

7. Inumpudi A, Srinivas M, Gupta DK. Telemedicine in pediatric surgery. Pediatr Surg Int 2001;17:436-41.

8. Susuki R, Otake S, Izutsu T, Yoshida M, Iwaya T. Monitoring daily living activities of elderly people in a nursing home using an infrared motion-detection system. Telemedicine and e-health 2006;12:146-55.

9. Haag-Heitman B, editor. Clinical practice development using novice to expert theory. Gaithersburg Md, Aspen: Jones and Bartlett publishers; 1999. p. 1-294. ISBN 0834212471.

10. Commission Directive 2005/28/EC of 8 April 2005 laying down principles and detailed guidelines for good clinical practice as regards investigational medicinal products for human use, as well as the requirements for authorisation of the manufacturing or importation of such products. Official Journal of the European Union 9.4.2005, L91/13-9. 